\title{
LexCult
}

DOI: https://doi.org/10.30749/2594-8261.v3n1p14-26

\section{A FRAGILIDADE DA SEGURANÇA PÚBLICA COMO FATOR DE INFLUÊNCIA NAS QUESTÕES ECONÔMICAS}

\section{THE FRAGILITY OF PUBLIC SECURITY AS A INFLUENCE FACTOR IN ECONOMIC ISSUES}

Reis Friede*

Resumo: O texto propõe uma reflexão sobre a relação entre desenvolvimento econômico e segurança pública. Demonstra como a ausência de parâmetros mínimos de segurança pública é um fator determinante para afetar o crescimento econômico e o desenvolvimento social, na medida em que estabelece uma relação negativa (consciente ou mesmo inconsciente) na equação "custo-benefício", própria da esfera do denominado ambiente de negócios. Serão relacionadas algumas notícias recentes publicadas na imprensa como forma de ilustrar sobre o impacto da falta de segurança na vida do cidadão e, consequentemente, na economia do País.

Palavras-chave: Segurança Pública. Desenvolvimento Econômico. Desenvolvimento Social.

Abstract: The text proposes a reflection on the relationship between economic development and public security. As the absence of minimum parameters of public security is a determining factor to affect economic growth and social development, insofar as it establishes a negative (conscious or even unconscious) relation in the "cost-benefit" equation, business environment. Some recent news published in the press will be related as a way to illustrate the impact of the lack of security in the life of the citizen and, consequently, in the economy of the Country.

Keywords: Public Safety. Economic development. Social development.

\footnotetext{
* Desembargador Federal, Presidente do Tribunal Regional Federal da $2^{\text {a }}$ Região (biênio 2019/21), Mestre e Doutor em Direito e Professor Adjunto da Universidade Federal do Estado do Rio de Janeiro (UNIRIO). Site: https://reisfriede.wordpress.com/. E-mail: reisfriede@hotmail.com.
} 


\section{INTRODUÇÃO}

No Brasil, o tema da corrupção é frequente e recorrente nos noticiários e também um fenômeno presente em nosso cotidiano, independente da camada social. A corrupção está presente na cultura de diferentes países, mas, no caso específico brasileiro, o contexto social e as diferentes relações de clientelismo, que nele são estabelecidas, acabam fazendo com que ela se propague com mais intensidade.

A palavra corrupção, que vem do latim corruptus, em seu sentido figurado significa "Degeneração moral; DEPRAVAÇÃO; IMORALIDADE; PERVERSÃO [Antôn.: decência, decoro, moralidade.]" (AULETE, [c2019]). A palavra é comumente usada para definir o ato de fazer uso do dinheiro público para seu próprio interesse, ou de algum parente ou amigo. Também se entende como corrupção quando a pessoa que ocupa um determinado cargo se utiliza de seu poder ou de sua autoridade para obter vantagem. Ela é um mal que assola diferentes países e se tornou tema de interesse e de prevenção e combate pela Organização das Nações Unidas (ONU):

Desde 1996, a corrupção começou a ser tema de interesse dos mais diferentes países que, de modo regional, iniciaram processos de acordos de ação conjunta nesse âmbito. Entretanto, as primeiras convenções firmadas não cobriam todas as regiões do mundo, deixando de lado grande parte dos países da Ásia e do Oriente Médio. Também alguns acordos apenas se referiam a abordagens específicas, como o suborno, por exemplo. Assim, a comunidade internacional manifestou $o$ interesse de delinear um acordo verdadeiramente global e capaz de prevenir e combater a corrupção em todas as suas formas. Assim, nasceu a Convenção das Nações Unidas contra a Corrupção. (UNITED NATIONS OFFICE ON DRUGS AND CRIME, c2019).

Mas até mesmo a corrupção - não obstante a gravidade de tal conduta e seus perversos efeitos para a economia de um país - não é fator absolutamente determinante para afetar o crescimento econômico e o desenvolvimento social. Entretanto, com toda certeza, a ausência de parâmetros (e, sobretudo, níveis) mínimos de segurança pública o é, na medida em que estabelece uma relação negativa (consciente ou mesmo inconsciente) na equação "custo-benefício", própria da esfera do denominado ambiente de negócios. 
Todas as nações do mundo que almejam, com autêntica sinceridade, um desenvolvimento socioeconômico verdadeiro (e, particularmente, sustentável), bem como inaugurar (ou mesmo reafirmar) um protagonismo internacional, estabelecendo, reforçando ou apenas tornando mais enfático o seu papel na governança global, não podem, em nenhuma hipótese, se eximir de um combate, sem tréguas, à corrupção, assim como à pior "doença" social que a humanidade, organizada em sociedade já experimentou e que responde pela (simplória) expressão designativa de insegurança pública.

Esta é a derradeira ameaça, que, a exemplo de um câncer em fase avançada de metástase, espalha-se pelo corpo social, encastelandose como um vírus em cada uma das células que compõem o tecido que é compartilhado por todos os integrantes da coletividade, putrefando, em última análise, o bem mais precioso que o ser humano possui em sua vida (e que se chama esperança), afastando, por via de consequência, os investidores (produtivos) que vivem, a exemplo de qualquer componente individual ou grupal humano, deste mesmo sentimento. (FRIEDE, 2017, informação verbal).

Evidentemente, não há como deixar de reconhecer que o problema da segurança pública no Brasil está entre os mais graves do mundo. Segundo dados divulgados no "Atlas da Violência 2018", pelo Instituto de Pesquisa Econômica Aplicada (IPEA) em colaboração com o Fórum Brasileiro de Segurança Pública (FBSP), no ano de 2016 o Brasil alcançou a marca histórica de 62.517 homicídios. Isso equivale a uma taxa de 30,3 mortes para cada 100 mil habitantes, que corresponde a 30 vezes a taxa da Europa. Apenas nos últimos dez anos, 553 mil pessoas perderam suas vidas devido à violência no Brasil - número superior aos mortos no conflito da Síria, país que se encontra formalmente em guerra civil. É preciso registrar que os números citados não contemplam outras 71 mil pessoas desaparecidas, muitas das quais, provavelmente, vítimas de homicídio (IPEA, 2018).

Verifica-se, no caso, aquilo que se convencionou chamar de subnotificação de registros, fenômeno que se soma ao complexo quadro acima, o que reflete, de modo geral, a ausência de capacidade apresentada pelo Estado até os dias atuais em manter a ordem pública.

Observa-se, portanto, um verdadeiro clima de "alerta geral", a afastar os investimentos produtivos, independentemente do fato de nosso País ostentar extraordinárias oportunidades de negócios, possuir a maior fronteira agrícola do mundo, ter mão de obra abundante, vastidão territorial pouco explorada e todos os 
demais requisitos básicos para fomentar o ambiente propício à prosperidade econômica.

Nesse cenário, resta evidente não haver as condições mínimas para a prosperidade econômica, tendo em vista a ausência de um ambiente propício à livre iniciativa, seja do capital ou do próprio trabalho, sendo certo reconhecer que, naqueles locais em que não é possível prover ordem e segurança, simplesmente inexiste espaço para o imprescindível desenvolvimento socioeconômico.

\section{SEGURANÇA PÚBLICA E O CRESCIMENTO ECONÔMICO}

A segurança pública e, portanto, a imposição da ordem estatal, com a correspondente efetividade do Ordenamento Jurídico, revela-se como condição indispensável para o crescimento e desenvolvimento econômicos. Sem a segurança da ordem pública e a consequente garantia da validade ampla e real da normatividade jurídica não se apresentam os pressupostos fundamentais que propiciam o investimento produtivo, com riscos relativamente aceitáveis.

Essas condições históricas, quando efetivamente existiram no Brasil, independentemente de outras considerações de matizes político-ideológicas, permitiram a derradeira viabilização do desenvolvimento econômico. Prova do que ora se afirma é que o ano de 1973 foi o período de doze meses em que o Brasil teve o maior crescimento econômico anual de sua história, atingindo extraordinários 13,9\% de crescimento do Produto Interno Bruto (PIB), taxa superior, inclusive, ao estrondoso e surpreendente crescimento da economia chinesa, que também é propiciada e turbinada por um ambiente de reconhecido controle no que concerne à segurança pública.

Durante todo o período em que os militares estiveram no poder (1964-1985), é cediço reconhecer que o crescimento econômico brasileiro foi o maior de toda a história nacional, atingindo uma taxa anual de crescimento do PIB superior à média de $7 \%$, o que permitiu alavancar nosso País da posição inicial de $46^{a}$ economia do mundo em 1964 - ocasião em que o PIB da Argentina, era, inclusive, maior que o brasileiro - para o $10^{\circ}$ lugar entre as maiores economias do planeta, o que reconhecidamente constituiu, nesse aspecto, uma verdadeira revolução. 
De forma diversa, no contexto atual, marcado pela crise de segurança pública, fica estrategicamente difícil, por exemplo, fabricar ou estocar produtos em grande escala, uma vez que essas mercadorias acabam por se tornar, nas fábricas ou nos estabelecimentos comerciais, objeto de cobiça da criminalidade dedicada aos crimes de furto e roubo, aumentando, consequentemente, os custos de produção e distribuição, reduzindo, assim, a produtividade e a competitividade, fatores indispensáveis ao crescimento econômico de forma geral. Tendo em vista os elevados índices de ocorrências criminais relativas a esses delitos, as empresas acabam por produzir manufaturados em menor quantidade, fazendo com que o preço individual de cada produto naturalmente se eleve.

Decorrente da crise da segurança pública, atualmente o roubo de cargas aparece como um dos principais causadores de preocupação para o setor econômico. Esse tipo de crime afeta a economia por causa de seu efeito em cadeia: os custos com as perdas provenientes do roubo precisam ser repassados para o consumidor final, encarecendo o preço das mercadorias e, consequentemente, limitando o seu consumo.

Estudo elaborado pela Federação das Indústrias do Estado do Rio de Janeiro (FIRJAN), intitulado "Quanto custa o roubo e o furto de cargas no Brasil", mostra que o aumento dos roubos de carga no país, entre 2011 e 2016, tiveram um impacto superior a $\mathrm{R} \$ 6,1$ bilhões.

Entre 2011 e 2016 foram registrados 97.786 roubos de cargas no Brasil, que geraram uma perda superior a $\mathrm{R} \$ 6,1$ bilhões. Este valor representa 5,1 vezes o investimento anunciado pelo governo federal em dezembro de 2016 para a modernização e ampliação do sistema penitenciário brasileiro nos próximos anos. Também equivale a todo o investimento previsto para as principais rodovias federais do estado do Rio de Janeiro na próxima década. (FEDERAÇÃO DAS INDÚSTRIAS DO ESTADO DO RIO DE JANEIRO, 2017).

Medidas mais severas precisam ser aplicadas para inibir esse tipo de ocorrência. Segundo o estudo da Firjan, três fatores vêm dificultando o combate ao roubo de cargas: a) a maior atuação de grandes organizações criminosas, que fazem disso uma forma de financiamento; b) ausência de ações que punam todos os elos dessa cadeia; c) carência de estrutura das forças de segurança que estão diretamente 
relacionadas ao combate a esse tipo de crime (FEDERAÇÃO DAS INDÚSTRIAS DO ESTADO DO RIO DE JANEIRO, 2017).

Por outro lado, os excessivos e desarrazoados mecanismos de regulação do Estado, em vez de funcionarem como salvaguarda contra o ambiente de insegurança pública, atuam, ao reverso, como fator de desestímulo aos investimentos produtivos, evitando que muitos produtos sejam adquiridos de modo legal - em função dos múltiplos controles burocráticos e cartoriais que o Estado impõe -, fazendo com que o mercado informal (muitas vezes alimentado pelas mercadorias provenientes dos roubos de cargas), desprovido dos exagerados e dispendiosos mecanismos regulatórios, cada vez mais tenha uma capacidade real de competir com o comércio formal, destruindo as bases da economia salutar, construtiva e fundada em um pacto social verdadeiramente democrático.

É notória a relação existente entre segurança pública e crescimento econômico, de modo que, quanto mais deficiente for a prestação desse serviço público essencial, menos crescimento o País experimentará.

\section{QUANDO A INSEGURANÇA SE FAZ PRESENTE}

A título de ilustração, serão elencadas algumas notícias recentes publicadas na grande imprensa como forma de levar a uma reflexão sobre o impacto da falta de segurança na vida do cidadão e, consequentemente, na vida econômica do País e de uma cidade.

A ineficiência na segurança pública impacta no setor de transportes públicos, problema que está alcançando até mesmo o tão novo sistema de BRT (Bus Rapid Transit), cuja organização inicial está dando lugar à completa desordem. Conforme notícia veiculada em 2017, o consórcio que administra o serviço (de BRT) na Cidade do Rio de Janeiro anunciou que poderia fechar a qualquer momento todas as 22 estações do eixo da Avenida Cesário de Melo, entre Campo Grande e Santa Cruz, em função da absoluta falta de segurança para garantir o pleno funcionamento do sistema. 
O Consórcio BRT alega que, nos últimos meses, as empresas proprietárias dos veículos articulados reduziram a frota e vêm tendo prejuízos seguidos por conta de estações depredadas por atos de vandalismo. A queda do número de usuários pagantes também é outro motivo alegado, não só pela evasão gerada por passageiros que driblam o sistema de segurança para entrar nas composições sem pagar, mas também pela concorrência com o transporte pirata. Problemas que, no cálculo das empresas, causam prejuízos de R\$ 800 mil por mês. Com quadro semelhante afetando outras linhas de BRTs, as perdas alcançam $\mathrm{R} \$ 1,4$ milhão. O consórcio acrescentou que, inicialmente, a intenção é manter serviços expressos entre a Rodoviária de Campo Grande e os bairros da Barra e do Recreio. Mas isso também depende de condições de segurança. Na realidade, das 22 estações sob risco, duas já estão inoperantes há meses devido a confrontos no entorno envolvendo traficantes e milicianos: Cesarão III e Vila Paciência. (MAGALHÃES, 2017).

Além das frequentes depredações, há relatos de que, por falta de fiscalização, diversos passageiros ingressam nas plataformas de embarque sem efetuar o devido pagamento da tarifa, pondo em risco a sobrevivência econômica do aludido modal, problema que pode culminar até mesmo na desativação de algumas estações.

Mais grave ainda é constatar que os corredores expressos do BRT estão sendo utilizados por carroças puxadas por animais, comprometendo, de modo contundente, a segurança viária. Da mesma forma, áreas destinadas a determinadas estações do modal em comento têm sido ocupadas pelo comércio irregular de ambulantes, que transformaram o espaço público em verdadeiros "mercadinhos".

Uma carroça puxada por um velho cavalo sacolejava, ontem pela manhã, no asfalto do corredor Transoeste, já desgastado pelo tempo de uso, levando pai e filha, que ignoravam solenemente a aproximação de um ônibus. O tempo parecia ter parado na Estação do BRT Santa Eugênia, em Paciência. Dentro da plataforma, um funcionário do sistema se limitava a observar o movimento de pessoas que entravam sem pagar passagem. Na Estação Cacique de Ramos, em Olaria, o cenário também é de abandono. A plataforma está fechada há dois meses, desde que foi depredada por um grupo de vândalos. Mesmo assim, motoristas continuam parando ali, para facilitar a vida de quem precisa desembarcar na região. A distância entre os degraus do ônibus (projetados para parar apenas nas estações) e o asfalto é grande, mas o risco de acidentes não impede que idosos e crianças se arrisquem, pulando na pista. [...]. A entrada de pessoas sem pagar a passagem virou rotina na Estação Santa Eugênia. Tanto que os motoristas não se espantam quando pessoas cruzam a pista e se apoiam nos ônibus para subir na plataforma. É o que acontece também em estações da região como a Curral Falso, em 
Santa Cruz. Na Estação Cesarinho, no mesmo bairro, não há mais ninguém para vender bilhetes. A plataforma foi transformada numa loja de ambulantes onde tudo é vendido, de balas a sanduíches e refrigerantes. Já a Estação Cesarão 3 é apenas um esqueleto do que já foi um dia. O equipamento está completamente destruído, com vidraças estilhaçadas e cacos ainda espalhados pelo chão. A depredação aconteceu há aproximadamente cinco meses. (ZUAZO; GOULART; RODRIGUES, 2017, p. 7).

Tendo em vista a crise de segurança pública, o segmento educacional (Escolas Parque e Corcovado, ambas localizadas na Zona Sul do Rio de Janeiro, por exemplo) está adotando iniciativas - que obviamente geram custos financeiros para o setor - destinadas a garantir a integridade física de seus alunos, professores e funcionários em casos de ocorrência de tiroteios nas proximidades de suas instalações, preparando-os (ou melhor, treinando-os) para situações que muito se assemelham às estratégias tomadas pela população civil (inglesa e alemã, por exemplo) durante os bombardeios ocorridos na Segunda Guerra Mundial (GOIS, 2018a, p. 8).

As medidas de salvaguarda implementadas pelas escolas não nos parecem exageradas, mormente se considerarmos que a Região Metropolitana do Rio de Janeiro teve 640 tiroteios só no primeiro mês de 2018, conforme relata a matéria de capa de O Globo, de 1 fev. 2018, o que nos dá uma média de 20 episódios por dia, confrontos que não raro acarretam mortes de pessoas inocentes e fechamento de vias públicas, tais como as Linhas Amarela e Vermelha e a Avenida Brasil, importantes vias de escoamento do trânsito da Cidade, cujos frequentes bloqueios levam pânico à população e causam sérios prejuízos à economia do Rio de Janeiro (A CRUEL..., 2018, p. 7).

Por volta das $16 \mathrm{~h}$ [do dia 25 jan. 2018], cerca de 50 mototaxistas saíram do Morro do Vidigal, ligado à Rocinha por uma mata, e fecharam os dois sentidos da Avenida Niemeyer. Em seguida, dezenas de pessoas tomaram a pista e montaram barricadas com pneus e pedaços de madeira. Motoristas, em pânico, tentavam sair dali de marcha a ré. Perto do Sheraton, um grupo ordenou que passageiros de um ônibus descessem e ateou fogo ao veículo. O que estava espalhado pelo asfalto também foi incendiado, assim como uma motocicleta que estava estacionada. As chamas alcançaram as grades da Ciclovia Tim Maia, e a fumaça podia ser vista da Praia de Ipanema. Moradores de um prédio, temendo uma tragédia, subiram 
para os andares mais altos. A situação só foi controlada por volta das $19 \mathrm{~h} 20 \mathrm{~m}$, quando um reboque e um trator removeram a carcaça do coletivo. (ROCINHA..., 2018, p. 8).

Em situações mais graves, quando a adoção de estratégias de proteção tornase insuficiente, a saída acaba sendo o próprio fechamento de estabelecimentos de ensino, tal como aconteceu com o Colégio Santa Mônica, no Rio de Janeiro, que por medida de segurança desativou a unidade localizada no Complexo da Maré, escola "que atendia somente alunos carentes, todos com bolsa integral" (GUERRA..., 2017, p. 18).

Por conta da insegurança pública, e devido ao aumento de roubos em condomínios cometidos por bandidos fingindo ser funcionários da Companhia Estadual de Gás (CEG), a concessionária mudou os protocolos de atendimentos ao usuário: "agora, quando o cliente marca uma visita técnica, recebe pelo WhatsApp a foto do técnico e uma senha, que o funcionário deve falar na portaria para provar sua identidade antes de subir" (GOIS, 2018).

Conforme se observa, esse quadro de insegurança acaba por incentivar a adoção, por parte das empresas, de uma série de providências destinadas a evitar a ação dos criminosos, fazendo com que o setor produtivo tenha de pagar "um preço elevado pelo aumento da violência no Rio de Janeiro", o que inclui não apenas "os custos diretos, resultantes de perdas por roubos e atos de vandalismo", mas também "os gastos com seguro e o reforço da segurança privada" (CAVALCANTI; ROSA, 2018, p. 27).

Instalação de geradores de energia para evitar perdas por corte de luz durante operações militares, mudança nos horários de troca de turno nas fábricas, jornada de produção encerrada mais cedo, executivos usando uniforme de técnicos ou operários, restrição de circulação de frota e funcionários em vias de alto risco, planos para blindar caminhões. A escalada da violência provocou mudanças na rotina de empresas instaladas no estado, resultando em custos extras e exigindo planejamento. A adoção de medidas para evitar situações de insegurança é ainda mais forte entre as multinacionais e os executivos estrangeiros, afirmam especialistas. (CAVALCANTI; ROSA, 2018, p. 27). 
Em um estado em que algumas fábricas instaladas na Baixada Fluminense, para não terem suas cargas roubadas, precisam "pagar uma espécie de mesada para os bandidos da região" (GOIS, 2018b, p. 10), não é de se estranhar que o comércio varejista carioca tenha gasto " $R \$ 1,5$ bilhão com segurança em 2017, um aumento de $25 \%$ em relação ao ano anterior", conforme dados obtidos pelo Clube de Diretores Lojistas, que "ouviu 750 lojistas das Zonas Norte, Oeste, Sul e Centro" (PIB..., 2018, p. 10).

Com centro de distribuição em Madureira, na Zona Norte, e fábrica em Queimados, na Baixada Fluminense, a Piraquê já gasta em torno de $\mathrm{R} \$ 1,5$ milhão por ano com segurança, sem considerar vendas perdidas devido a roubo de carga, conta ALEXANDRE COLOMBO, diretor de marketing da empresa: - Dobramos o efetivo na escolta dos caminhões. Mas os roubos, mesmo com a intervenção, persistem. Já tivemos seis ou sete este ano. Em 2017, houve ao menos um por semana. Foram 53 no ano. Gastamos $70 \%$ mais para renovar o seguro da carga. (CAVALCANTI; ROSA, 2018, p. 27).

Em relação ao roubo de cargas no Estado do Rio de Janeiro, dados do Instituto de Segurança Pública (ISP), compilados por Luiz Ernesto Magalhães (2017), apontam que o "número total de ocorrência é o maior em três décadas", sendo que, nos "11 primeiros meses de 2017, foram 212.065 casos - uma média de 27 por hora" (MAGALHÃES, 2017, p. 15).

Esse quadro também esclarece o motivo pelo qual o carnaval do Rio atraiu, em 2018, apenas 1,1 milhão de turistas, enquanto que o de Veneza conseguiu atrair 3 milhões de pessoas (RIO..., 2018, p. 11).

Ademais, a insegurança afugenta a celebração de novos negócios no Estado do Rio de Janeiro, conforme reconhece, inclusive, Luiza Helena Trajano, Presidente do Conselho de Administração do grupo Magazine Luiza, que "tem perto de 800 filiais no país e nenhuma no Rio" (CAVALCANTI; ROSA, 2018, p. 27). Minha tia, que fundou a empresa, tinha muito medo do Rio de Janeiro. Ela sempre falava: "No Rio, não é para montar loja por causa da violência". (CAVALCANTI; ROSA, 2018, p. 27).

Nem mesmo carros-fortes estão a salvo do terror imposto pelos criminosos. De acordo com a matéria elaborada por Patrik Camporez (2018), e segundo relatórios internos do setor de transportes de valores, " $90 \%$ das ações dos bandidos são feitas 
por meio do uso de explosivos contrabandeados ou desviados da atividade de exploração mineral", sendo que, entre 2015 e 2017 (até o mês de setembro), "85,3 toneladas de explosivos clandestinos foram apreendidos no País em operações federais", figurando o Rio de Janeiro no topo deste ranking. E a mesma lógica que "empurra os assaltos aos carros-fortes atinge os caixas eletrônicos, principalmente os de pequenos negócios de periferia e pouco vigiados", gerando elevados custos para a rede bancária (CAMPOREZ, 2018, p. 3).

A onda de crimes contra a rede bancária obrigou o setor a ampliar o gasto com segurança: $\mathrm{R} \$ 9$ bilhões foram aplicados nos últimos anos. A Febraban diz que acompanha os ataques a caixas eletrônicos com extrema preocupação, apesar da queda no número de assalto a agências. A entidade diz que o dano das explosões força as instituições financeiras a reformar o local e a repor os equipamentos danificados. (CAMPOREZ, 2018, p. 3).

Como se vê, os casos concretos acima mencionados demonstram, em primeiro lugar, como o País, por conta da insegurança pública, perde inúmeras oportunidades de negócios. Da mesma forma, sinalizam que o problema ora abordado acarreta um aumento de custos para as empresas, custo esse que, consequentemente, é repassado ao consumidor final.

\section{CONSIDERAÇÕES FINAIS}

Não obstante o indiscutível potencial econômico brasileiro, em função de seu amplo território (o $5^{\circ}$ maior do mundo, com $8.516 .000 \mathrm{~km}^{2}$ ), grande população (a $6^{\mathrm{a}}$ maior, com 208 milhões de habitantes, segundo levantamento divulgado pelo IBGE em 27 fev. 2018), farta mão de obra (ainda que, reconhecidamente, não devidamente qualificada) e maior fronteira agrícola (ainda a ser explorada) do planeta, é fato que todas essas qualidades acabam por se tornar secundárias e pouco atrativas, em função da real e permanente crise de credibilidade que paira sobre o Brasil pelos mais diversos motivos, mas, fundamentalmente, por não conseguirmos impor a condição básica para o crescimento e desenvolvimento econômicos, a qual responde pelo singelo nome de segurança, no seu mais amplo sentido, abrangendo não só a segurança pública, mas, também, a segurança e efetividade jurídicas. 
É o momento, portanto, de se refletir a respeito das prioridades nacionais, focando no combate sem tréguas ao clima de insegurança (pública e jurídica), fazendo valer a máxima inscrita na bandeira nacional, e que preconiza, em efetiva análise, a ordem como condição indispensável para o progresso.

A história é rica em demonstrar, com sólidos argumentos e dados, que a consolidação do desenvolvimento e do crescimento econômico, em todas as nações que celebraram seu exitoso advento, somente se revelou possível após a imposição da ordem pública estatal, independentemente da forma exteriorizante como foi implantada e, sobretudo, consolidada.

Por efeito conclusivo, resta reconhecer que enquanto não for resolvido o gravíssimo problema da segurança pública, o Brasil estará irremediavelmente condenado às baixas taxas de crescimento e, consequentemente, a uma condição de subdesenvolvimento anacrônico.

\section{REFERÊNCIAS}

A CRUEL realidade dos cariocas. O Globo, Rio de Janeiro, 7 fev. 2018, p. 7.

AULETE, Caldas. Aulete digital: dicionário contemporâneo da língua portuguesa. [c2019]. Disponível em: http://www.aulete.com.br/index.php. Acesso em: 6 maio 2019.

CAMPOREZ, Patrik. Quando nem Mesmo Carros-Fortes Estão a Salvo. O Globo, Rio de Janeiro, 12 fev. 2018, p. 3.

CAVALCANTI, Glauce; ROSA, Bruno. Novo Código de Conduta. O Globo, 11 mar. 2018, p. 27.

FEDERAÇÃO DAS INDÚSTRIAS DO ESTADO DO RIO DE JANEIRO. Quanto custa o roubo e o furto de cargas no Brasil. Disponível em:

https://www.firjan.com.br/publicacoes/publicacoes-de-economia/o-impactoeconomico-do-roubo-de-cargas-no-brasil.htm. Acesso: 5 maio 2019.

GUERRA do Rio. O Globo, Rio de Janeiro, 17 dez. 2017, p. 18.

IPEA. Atlas da Violência. Instituto de Pesquisa Econômica Aplicada, 2018.

FRIEDE, Reis. Democracia e Regime Democrático. Rio de Janeiro, Escola Naval, 22 mar. 2017. (comunicação oral). 
GOIS, Ancelmo. A Guerra do Rio. O Globo, Rio de Janeiro, 30 jan. 2018a, p. 8.

GOIS, Ancelmo. A Síria dos Trópicos I. O Globo, Rio de Janeiro, 2 fev. 2018b, p. 10.

GOIS, Ancelmo. Já tem seguradora oferecendo seguro às... vítimas de crimes. $\mathbf{O}$ Globo, Rio de Janeiro, 8 abr. 2018.

MAGALHÃES, Luiz Ernesto. Sucesso do BRT em 22 Estações da Zona Oeste que Podem Ser Fechadas Foi Passageiro. O Globo, Rio de Janeiro, 10 nov. 2017.

MAGALHÃES, Luiz Ernesto. Um Recorde que Ninguém Quer. O Globo, Rio de Janeiro, 16 dez. 2017, p. 15

PIB do Crime Sobe 25\%. O Globo, Rio de Janeiro, 23 fev. 2018, p. 10.

RIO teve 640 tiroteios só no primeiro mês do ano. O Globo, Rio de Janeiro, 2 fev. 2018, p. 11.

ROCINHA em estado de sítio. O Globo, Rio de Janeiro, 26 jan. 2018, p. 8.

UNITED NATIONS OFFICE ON DRUGS AND CRIME. Convenção das Nações Unidas contra a Corrupção. c2019. Disponível em: https://www.unodc.org/lpobrazil/pt/corrupcao/convencao.html. Acesso: 13 maio 2019.

ZUAZO, Pedro, GOULART, Gustavo; RODRIGUES, Renan. A que Ponto Chegamos. O Globo, 29 dez. 2017, p. 7. 